\title{
Aerodynamic Drag and Rolling Resistance of Three-Wheelers
}

\section{J.A.K.S. Jayasinghe, B.S. Samarasiri and G.M.A.I. Rajakaruna}

Abstract: Three-wheelers are popular in Sri Lankan roads as a convenient mode of transportation. Presently there are about 500,000 registered three-wheelers. The range of commercially available electric vehicles are limited due to their battery weight and hence used mostly as neighbourhood vehicles. Three-wheelers are used mostly as neighbourhood vehicles and hence ideal for electrification. But no successful commercial electrically powered three-wheeler is available yet. Aerodynamic drag coefficient and rolling resistance coefficient are two basic parameters needed to determine the motor capacity of an electric vehicle. Accurate values of aerodynamic drag coefficient and rolling resistant coefficient are important to calculate accurate power estimate in electric vehicle design. In this paper we present an accurate method to determine the aerodynamic drag coefficient and rolling resistance coefficient of commonly available three-wheelers in Sri Lanka.

Keywords: Aerodynamic drag coefficient, rolling resistance coefficient

\section{Introduction}

Aerodynamic Drag coefficient $\left(C_{d}\right)$ and rolling resistance coefficient $(\mu)$ are very important basic parameters for designing energy efficient vehicles. Aerodynamic drag coefficient varies from 0.30 to 0.35 for modern cars, from 0.33 to 0.35 for modern vans and from 0.42 to 0.46 for modern pick-ups [1]. These parameters are obtained by carrying out a coast-down test where vehicle is driven to a reasonable high speed, put into neutral gear if possible, and left to roll unrestricted to a complete stop on a levelled dry asphaltcovered road[3]. Then with the aid of the speed-time graph, mean velocity and mean acceleration at a relatively high speed $\left(50 \mathrm{kmh}^{-1}\right)$ and relatively low speed $\left(10 \mathrm{kmh}^{-1}\right)$ are estimated to determine the above two parameters. Although this is a relatively simple method, it does not give accurate results for light weight vehicles like threewheelers because for light weight vehicles, especially at low speeds, imperfect road conditions create significant speed variations. This paper presents an accurate methodology for determining $C_{d}$ and $\mu$ for low weight vehicles such as three-wheelers.

\section{Methodology}

The aerodynamic drag coefficient and rolling resistance creates forces $F_{n}$ and $F_{\mathrm{r}}$ respectively to decelerate the vehicle as follows:

$$
F_{a}=0.5 \rho C_{d} A\left(v-v_{0}\right)^{2}
$$

Where,

$\rho$ - Air density $\left(\mathrm{kgm}^{-3}\right)$

$C_{d}$ - Drag coefficient

A - Frontal projected area of the vehicle $\left(\mathrm{m}^{2}\right)$

$v$ - Vehicle speed $\left(\mathrm{ms}^{-1}\right)$

$v_{0}-$ Wind Speed $\left(\mathrm{ms}^{-1}\right)$

Eng. Prof. JAKS Jayasinghe, BSc (Eng.), MEE, PhD, MIE (Sri Lanka) graduated from the University of Moratuwa(UOM) Sri Lanka in 1984. He obtained his MEE in Electronics Engineering in 1987 from Nefherland University Foundation For Intermational Corporation and $P h D$ from University of Twente in 1991. Prof. Jayasinglie attached to Department of Electronic \& Telecommunication Engineering, University of Moratuwn served as Senior Lecturer up to 2001 and thereafter as Professor in Electronic \& Telecommunication Engineering up to date.

Eng. B S. Samarasiri, BSc (Eng), CEng, MIE (Sri Lanka) graduated from the University of Sri Lanka Katubedda Campus in 1977 with a first class honours in the field of Electronic and Telecommunication engineering. He commenced his academic career in $1978 \mathrm{at}$ the department of Electronic and Teleconmminication enginteering of the University of Moratuwa. He persued his postgraduate training in the field of Bio-Medical and Systems Engineering at the Unizersity of New South Wules - Australia. Since 2000 to date he serves as the Director of the Engineering Design Centre (EDC) of the University of Moratuwn.

G M A I Rajakaruna, B.Si (Eng.), Hons, Presently Design Engmeer, Engineering Design Centre, University of Moratiwa 
Where,

$\mu$ - Rolling resistance

$\alpha$ - Inclination angle (degree)

$$
\left.v=\left(\sqrt{\frac{\mu m g}{0.5 \rho C_{d} A}}\right) \cdot \tan \left(\frac{\left(\sqrt{\frac{\mu m g}{0.5 \rho C_{d} A}}\right)}{\left(\frac{m}{0.5 \rho C_{d} A}\right)}\right)\left(t_{c}-t\right)\right)
$$

- Weight of the vehicle $(\mathrm{kg})$

Hence, following differential equation will describe the behaviour of the vehicle during coast-down test at zero wind speed on a flat road.

$m \frac{d v}{d t}=0.5 \rho C_{d} A v^{2}+\mu m g$

Then by defining two constants $C_{1}$ and $C_{2}$,

$$
\begin{gathered}
C_{1}=\frac{m}{0.5 \rho C_{d} A} \\
C_{2}=\sqrt{\frac{\mu m g}{0.5 \rho C_{d} A}}
\end{gathered}
$$

The differential equation can be simplified as

$$
C_{1} \frac{d v}{d t}=v^{2}+C_{2}^{2}
$$

The general solution to the above differential equation can be expressed as

$$
v=C_{2} \tan \left(K-\left(\frac{C_{2}}{C_{1}}\right) t\right)
$$

$K$ is a constant

Taking the boundary condition $v=0$ at $t=t_{e}$

$t_{e}=$ End time

$$
K=\left(\frac{C_{2}}{C_{1}}\right) t_{e}
$$

The reduction in the velocity of the vehicle during the coast-down test can finally be described as

$$
v=C_{2} \tan \left(\left(\frac{C_{2}}{C_{1}}\right)\left(t_{e}-t\right)\right)
$$

Substituting $C_{1}$ and $C_{2}$ values to Equation 9

$C_{d}$ and $\mu$ are only two unknowns in this equation.

\section{Parameter Estimation and Verification for a Flat-Even Road}

The following data is applicable for a commonly used three-wheeler:

\author{
Mass (m): $500 \mathrm{~kg}$ \\ Frontal projected area ( $\square): 1.595 \mathrm{~m}^{2}$
}

Taking Air Density $(\rho)$ as $1.1613 \mathrm{kgm}^{-3}$ at an elevation of zero meters and ambient temperature of $30{ }^{\circ} \mathrm{C}, \mathrm{C}_{1}$ and $\mathrm{C}_{2}$ can be expressed as

$$
\begin{aligned}
& C_{1}=\frac{539.8770}{C_{d}} \\
& C_{2}=72.7366 \cdot \sqrt{\frac{\mu}{C_{d}}}
\end{aligned}
$$

Hence, the three-wheeler speed during the coast-down test can be given as

$$
v=72.7366 \sqrt{\frac{\mu}{C_{d}}} \cdot \tan \left(\left(0.1347 \sqrt{C_{d} \mu}\right)\left(t_{e}-t\right)\right)
$$

With these non-linear relationships, extraction of parameters $C_{d}$ and $\mu$ from a measured data set is very difficult. The best way to extract parameters is by selecting the best curve from a set of theoretical plots generated for a number of $C_{d}$ and $\mu$ values giving the minimum Mean Square Error (MSE) and the largest correlation coefficient with the measured data set. Figure 1 depicts the graph for a typical measurement carried out using an electronic data logger develop by us for a three wheeler with the best fitting theoretical graph having MSE of 0.7562 and correlation coefficient of 0.9992. According to results tabulated in Table 1, the drag coefficient of the vehicle is 0.4080 and the rolling resistance coefficient is 0.0169 . The values obtained by 
the method described in [2] are 0.4702 and 0.0166 respectively. The MSE for the above result is 1.9485 and the correlation coefficient is 0.9987. The results obtained from the two methods show a significant agreement for an even road compared to results presented in Section 4 for an uneven road.

\begin{tabular}{|c|c|c|c|c|}
\hline \multirow{2}{*}{} & \multicolumn{2}{|c|}{$\begin{array}{c}\text { Proposed } \\
\text { Method }\end{array}$} & \multicolumn{2}{c|}{$\begin{array}{c}\text { Method } \\
\text { described in [2] }\end{array}$} \\
\cline { 2 - 5 } & $C_{d}$ & $\mu\urcorner$ & $C_{d}$ & $\mu\urcorner$ \\
\cline { 2 - 5 } & 0.4080 & 0.0169 & 0.4702 & 0.0166 \\
\hline $\begin{array}{c}\text { Correlation } \\
\text { coefficient }\end{array}$ & \multicolumn{2}{|c|}{0.9992} & \multicolumn{2}{|c|}{$\mathbf{0 . 9 9 8 7}$} \\
\hline $\begin{array}{c}\text { Mean } \\
\text { square } \\
\text { error }\end{array}$ & \multicolumn{2}{|c|}{0.7562} & \multicolumn{2}{|c|}{1.9485} \\
\hline
\end{tabular}

Table 1- $C_{d}$ and $\mu$ values estimated from two independent methods for a flat-even road

\section{Parameter Estimation for a Flat- Uneven Road}

Three-wheeler is a light vehicle and surface irregularities of the road affect vehicle speed in a significant manner. In the method described in [2], parameters are estimated using the mean velocity and mean acceleration at a relatively high speed point and relatively low speed point and hence the surface irregularities introduce significant errors. Table 2 shows estimated $C_{d}$ and $\mu$ values using proposed method and method described in [2] for four different attempts on the same road. A large variation is observed for $C_{d}$ and $\mu$ obtained from the method described in [2] whereas less variation is observed for the values estimated from proposed method.
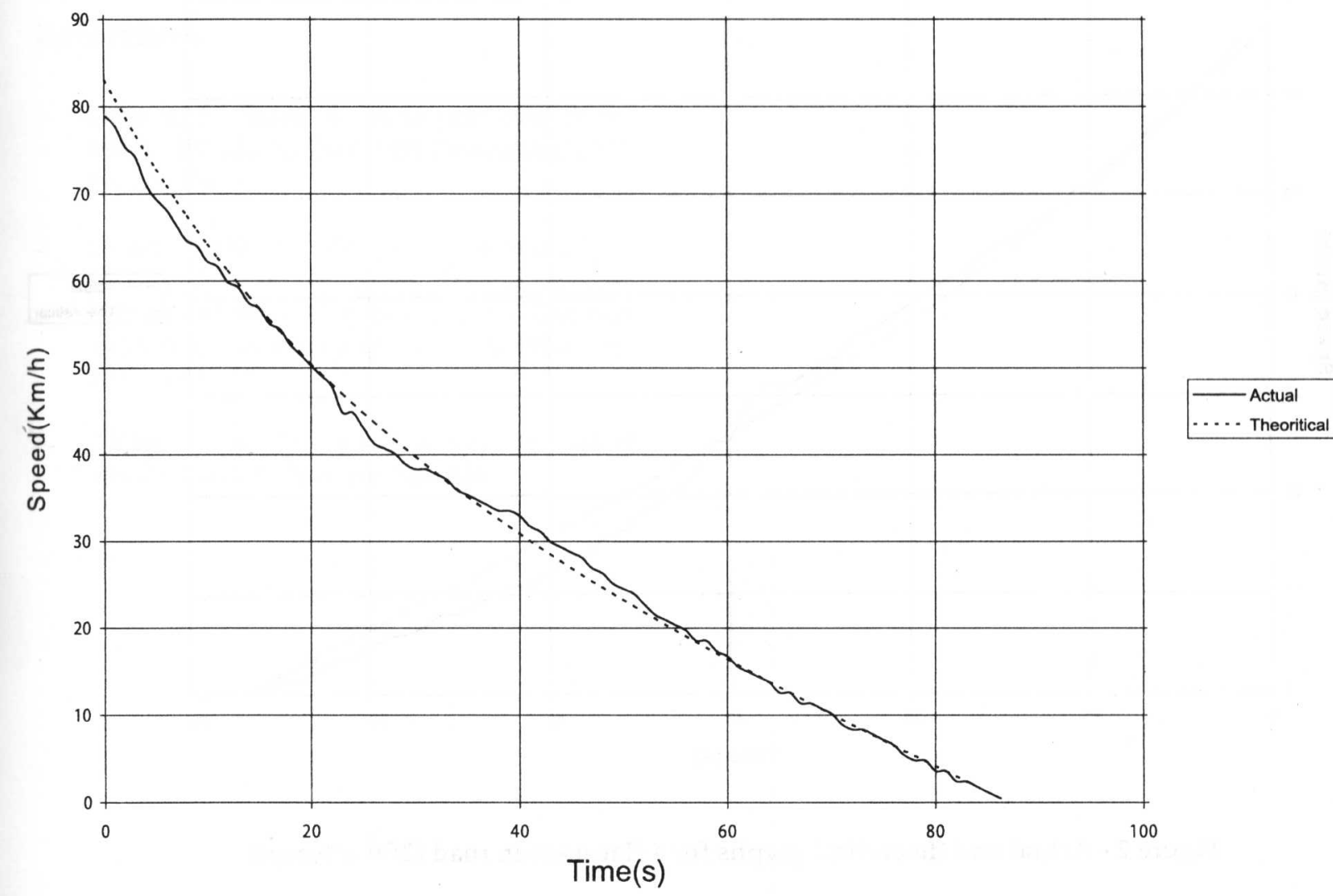

Figure 1 - Actual and theoretical graphs for a flat-even road 
Table 2 - Optimum $C_{d}$ and $\mu$ values for a flat-uneven road

\begin{tabular}{|c|c|c|c|c|c|c|c|c|}
\hline & \multicolumn{4}{|c|}{ Proposed Method } & \multicolumn{4}{c|}{ Method Described in [2] } \\
\hline Attempt & $C_{d}$ & $\mu$ & $\begin{array}{c}\text { Correlation } \\
\text { Coefficient }\end{array}$ & $\begin{array}{c}\text { Mean } \\
\text { square } \\
\text { error }\end{array}$ & $C_{d}$ & $\mu$ & $\begin{array}{c}\text { Correlation } \\
\text { Coefficient }\end{array}$ & $\begin{array}{c}\text { Mean } \\
\text { square } \\
\text { error }\end{array}$ \\
\hline $1^{\text {st }}$ & 0.5800 & 0.02680 & 0.9985 & 0.1942 & 0.5758 & 0.0204 & 0.9983 & 10.7078 \\
\hline $2^{\text {nd }}$ & 0.5300 & 0.02800 & 0.9989 & 0.1562 & 0.6027 & 0.0218 & 0.9987 & 6.6676 \\
\hline $3^{\text {rd }}$ & 0.5500 & 0.0300 & 0.9983 & 0.1715 & 0.4448 & 0.0334 & 0.9985 & 1.1438 \\
\hline $4^{\text {th }}$ & 0.5700 & 0.0270 & 0.9988 & 0.2303 & 0.4125 & 0.0300 & 0.9984 & 1.0599 \\
\hline Average & 0.5575 & 0.0279 & & & 0.5089 & 0.0264 & & \\
\cline { 1 - 1 } Standard \\
Deviation & 0.0192 & 0.0013 & & & 0.0817 & 0.0055 & & \\
\hline
\end{tabular}

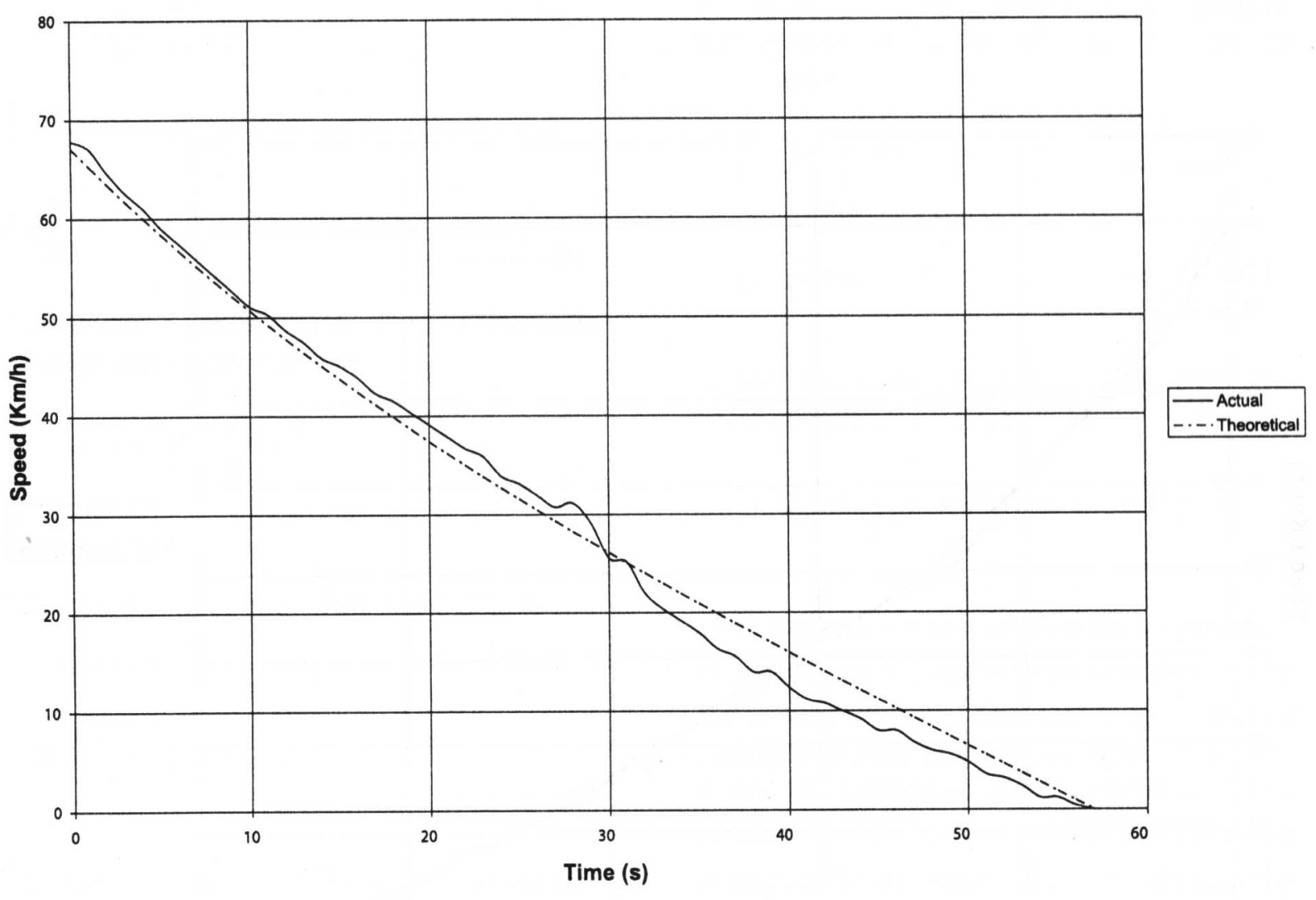

Figure 2 - Actual and theoretical graphs for a flat-uneven road ( ${ }^{\text {nd }}$ attempt) 


\section{Conclusions}

Surface irregularities of the roads tend to change the speed of light weight vehicles such as three-wheelers during coast-down test. These speed variations create significant changes to the calculation of aerodynamic drag coefficient and rolling resistance by the methods presented in literature. For example, using the method described in [2], the aerodynamic drag coefficient was found to be 0.5089 and rolling resistance was 0.0264 with a standard deviation of 0.0817 and 0.0055 respectively for our test vehicle. For the same test, using the new method in this paper, we have obtained aerodynamic drag coefficient and rolling resistance as 0.5575 and 0.0279 with a standard deviation of $0.0192,0.0013$ respectively. Therefore, the method presented in this paper is better suited to determine aerodynamic drag coefficient and rolling resistance of light weight vehicles such as three-wheelers.

\section{References}

1. Leitman, S., Brant, B., Build your own electric vehicle, 2nd ed., McGraw-Hill Companies, 2009, pp. 104-106.

2. Daniel Northcott "Design, Simulation, and Construction of A Series Hybrid Electric Vehicle", Department of Electrical and Computer Engineering, University of Manitoba, Winnipeg. 2007, pp- 15-18.

3. Miller J. M., Propulsion systems for hybrid vehicles, IET, UK, 2004, pp. 224- 226. 
Appendix A: Example empirical calculation using method described in [2]

Table A1 - Case example for empirical calculation of $C_{d}$ and $\mu$

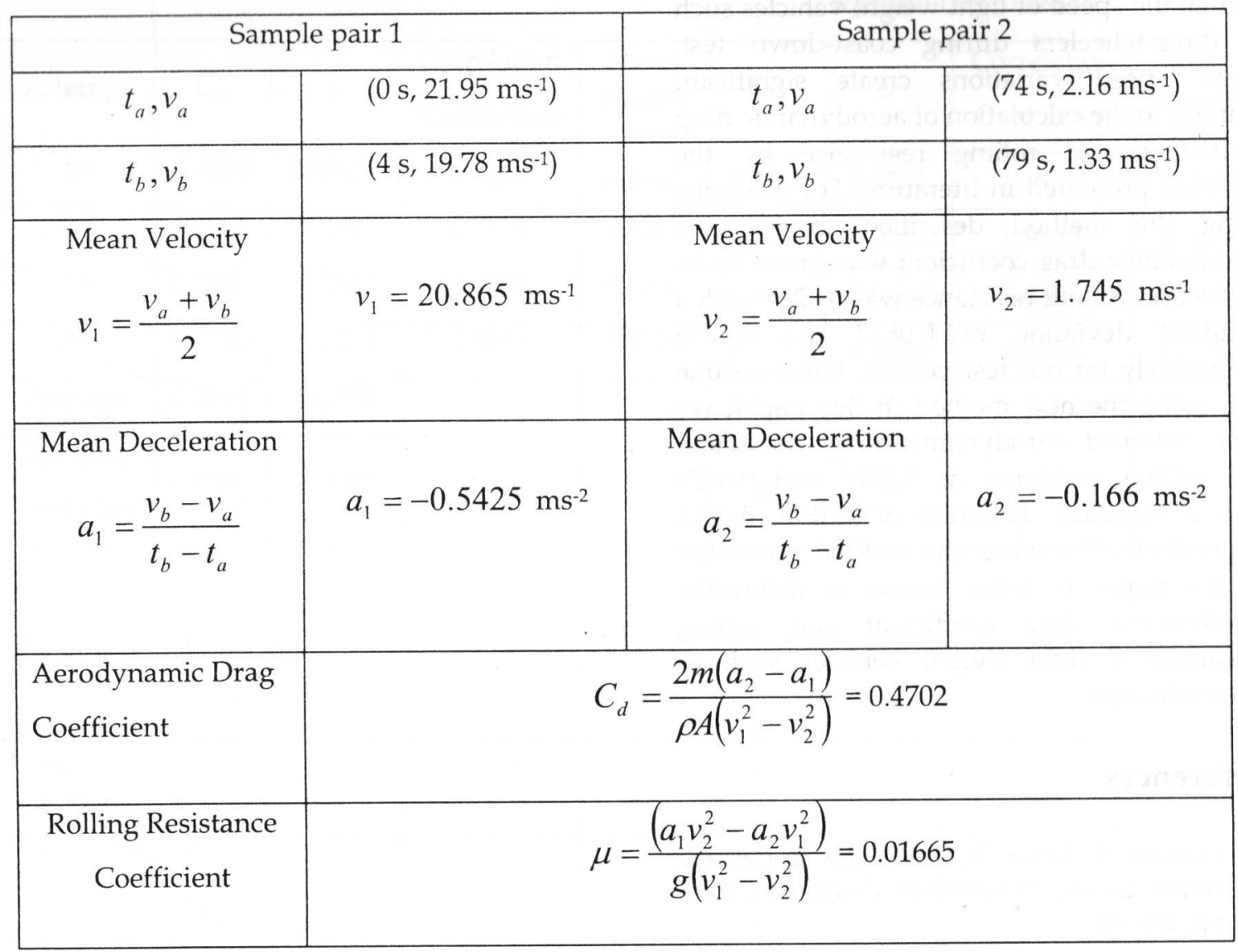


Appendix B: Coast-down test data for a three wheeler

Table B1 - Measured Velocity for a Flat-Even Road

\begin{tabular}{|c|c|c|c|c|c|}
\hline Time(s) & $\operatorname{Velocity}\left(\mathrm{ms}^{-1}\right)$ & Time(s) & $\operatorname{Velocity}\left(\mathrm{ms}^{-1}\right)$ & Time(s) & $\operatorname{Velocity}\left(\mathrm{ms}^{-1}\right)$ \\
\hline 0 & 21.95 & 30 & 10.64 & 60 & 4.66 \\
\hline 1 & 21.61 & 31 & 10.64 & 61 & 4.32 \\
\hline 2 & 20.95 & 32 & 10.47 & 62 & 4.16 \\
\hline 3 & 20.62 & 33 & 10.31 & 63 & 3.99 \\
\hline 4 & 19.78 & 34 & 9.98 & 64 & 3.82 \\
\hline 5 & 19.29 & 35 & 9.81 & 65 & 3.49 \\
\hline 6 & 18.95 & 36 & 9.64 & 66 & 3.49 \\
\hline 7 & 18.45 & 37 & 9.48 & 67 & 3.16 \\
\hline 8 & 17.96 & 38 & 9.31 & 68 & 3.16 \\
\hline 9 & 17.79 & 39 & 9.31 & 69 & 2.99 \\
\hline 10 & 17.29 & 40 & 9.14 & 70 & 2.83 \\
\hline 11 & 17.12 & 41 & 8.81 & 71 & 2.49 \\
\hline 12 & 16.63 & 42 & 8.65 & 72 & 2.33 \\
\hline 13 & 16.46 & 43 & 8.31 & 73 & 2.33 \\
\hline 14 & 15.96 & 44 & 8.15 & 74 & 2.16 \\
\hline 15 & 15.79 & 45 & 7.98 & 75 & 2.00 \\
\hline 16 & 15.30 & 46 & 7.81 & 76 & 1.83 \\
\hline 17 & 15.13 & 47 & 7.48 & 77 & 1.50 \\
\hline 18 & 14.63 & 48 & 7.32 & 78 & 1.33 \\
\hline 19 & 14.30 & 49 & 6.98 & 79 & 1.33 \\
\hline 20 & 13.97 & 50 & 6.82 & 80 & 1.00 \\
\hline 21 & 13.63 & 51 & 6.65 & 81 & 1.00 \\
\hline 22 & 13.30 & 52 & 6.32 & 82 & 0.67 \\
\hline 23 & 12.47 & 53 & 5.99 & 83 & 0.67 \\
\hline 24 & 12.47 & 54 & 5.82 & 84 & 0.50 \\
\hline 25 & 11.97 & 55 & 5.65 & 85 & 0.33 \\
\hline 26 & 11.47 & 56 & 5.49 & 86 & 0.17 \\
\hline 27 & 11.31 & 57 & 5.15 & 87 & 0.00 \\
\hline 28 & 11.14 & 58 & 5.15 & & \\
\hline 29 & 10.81 & 59 & 4.82 & & \\
\hline
\end{tabular}


Table B2 - Measured velocity for a Flat-Uneven Road

\begin{tabular}{|c|c|c|c|c|c|c|c|c|c|}
\hline $\begin{array}{l}\text { Time } \\
\text { (s) }\end{array}$ & $\begin{array}{c}\text { Attempt } \\
1 \\
\text { Velocity } \\
\left(\mathrm{ms}^{-1}\right)\end{array}$ & $\begin{array}{l}\text { Attempt } \\
\quad 2 \\
\text { Velocity } \\
\left(\mathrm{ms}^{-1}\right)\end{array}$ & $\begin{array}{c}\text { Attempt } \\
3 \\
\text { Velocity } \\
\left(\mathrm{ms}^{-1}\right)\end{array}$ & $\begin{array}{c}\text { Attempt } \\
\quad 4 \\
\text { Velocity } \\
\left(\mathrm{ms}^{-1}\right)\end{array}$ & $\begin{array}{c}\text { Time } \\
\text { (s) }\end{array}$ & $\begin{array}{c}\text { Attempt } \\
1 \\
\text { Velocity } \\
\left(\mathrm{ms}^{-1}\right)\end{array}$ & $\begin{array}{c}\text { Attempt } \\
2 \\
\text { Velocity } \\
\left(\mathrm{ms}^{-1}\right)\end{array}$ & $\begin{array}{c}\text { Attempt } \\
3 \\
\text { Velocity } \\
\left(\mathrm{ms}^{-1}\right)\end{array}$ & $\begin{array}{c}\text { Attempt } \\
4 \\
\text { Velocity } \\
\left(\mathrm{ms}^{-1}\right)\end{array}$ \\
\hline 0 & 21.39 & 21.17 & 20.39 & 20.73 & 29 & 7.09 & 7.20 & 5.99 & 6.98 \\
\hline 1 & 20.84 & 20.73 & 19.84 & 20.17 & 30 & 7.20 & 6.54 & 5.65 & 6.65 \\
\hline 2 & 20.28 & 19.95 & 19.17 & 19.62 & 31 & 6.54 & 6.10 & 5.43 & 6.76 \\
\hline 3 & 19.51 & 19.17 & 18.51 & 18.84 & 32 & 6.10 & 5.87 & 5.10 & 6.21 \\
\hline 4 & 18.95 & 18.51 & 17.73 & 18.29 & 33 & 5.87 & 5.43 & 4.77 & 5.87 \\
\hline 5 & 18.29 & 17.84 & 17.29 & 17.84 & 34 & 5.43 & 5.21 & 4.43 & 5.43 \\
\hline 6 & 17.84 & 17.29 & 16.74 & 17.29 & 35 & 5.21 & 4.88 & 4.21 & 5.32 \\
\hline 7 & 17.29 & 16.85 & 16.29 & 16.85 & 36 & 4.88 & 4.66 & 3.66 & 4.88 \\
\hline 8 & 16.85 & 16.40 & 15.74 & 16.40 & 37 & 4.77 & 4.43 & 3.66 & 4.66 \\
\hline 9 & 16.40 & 15.85 & 15.30 & 15.96 & 38 & 4.32 & 4.32 & 3.77 & 4.32 \\
\hline 10 & 15.85 & 15.52 & 14.85 & 15.41 & 39 & 4.10 & 3.77 & 2.99 & 4.43 \\
\hline 11 & 15.41 & 14.96 & 14.41 & 14.96 & 40 & 3.99 & 3.99 & 2.77 & 3.77 \\
\hline 12 & 14.96 & 14.52 & 13.97 & 14.52 & 41 & 3.77 & 3.33 & 2.44 & 3.66 \\
\hline 13 & 14.41 & 13.97 & 13.52 & 13.97 & 42 & 3.55 & 3.21 & 2.44 & 3.44 \\
\hline 14 & 14.08 & 13.63 & 13.08 & 13.52 & 43 & 2.99 & 2.88 & 2.00 & 2.88 \\
\hline 15 & 13.63 & 13.08 & 12.64 & 13.08 & 44 & 2.88 & 2.66 & 1.77 & 2.77 \\
\hline 16 & 13.19 & 12.75 & 12.19 & 12.64 & 45 & 2.66 & 2.33 & 1.66 & 2.55 \\
\hline 17 & 12.75 & 12.30 & 11.86 & 12.08 & 46 & 2.44 & 2.11 & 1.11 & 2.22 \\
\hline 18 & 12.30 & 11.86 & 11.31 & 11.64 & 47 & 2.22 & 2.00 & 1.11 & 1.88 \\
\hline 19 & 11.75 & 11.31 & 10.86 & 10.97 & 48 & 1.77 & 1.66 & 0.78 & 1.66 \\
\hline 20 & 11.31 & 10.97 & 10.42 & 10.53 & 49 & 1.44 & 1.33 & 0.33 & 1.44 \\
\hline 21 & 10.86 & 10.42 & 9.98 & 9.86 & 50 & 1.55 & 1.33 & 0.11 & 1.22 \\
\hline 22 & 10.42 & 9.98 & 9.31 & 9.31 & 51 & 1.11 & 0.89 & 0.00 & 0.89 \\
\hline 23 & 9.75 & 9.53 & 8.87 & 8.98 & 52 & 0.78 & 0.78 & - & 0.78 \\
\hline 24 & 9.09 & 8.87 & 8.20 & 8.53 & 53 & 0.44 & 0.55 & - & 0.44 \\
\hline 25 & 8.76 & 8.98 & 7.87 & 8.09 & 54 & 0.33 & 0.11 &. & 0.33 \\
\hline 26 & 8.31 & 8.20 & 7.76 & 7.76 & 55 & 0.11 & 0.00 & - & 0.11 \\
\hline 27 & 8.42 & 7.98 & 6.76 & 8.31 & 56 & 0.00 & - & - & 0.00 \\
\hline 28 & 7.32 & 7.65 & 7.20 & 7.32 & & & & & \\
\hline
\end{tabular}


Table B3 - Selected data sets to calculate $C_{d}$ and $\mu$ for flat-uneven road by method in [2]

\begin{tabular}{|l|l|l|l|l|}
\hline & \multicolumn{3}{|l|}{ Sample pair 1 } & Sample pair 2 \\
\hline \multirow{3}{*}{$1^{\text {st }}$ Attempt } & $t_{a}, v_{a}$ & $\left(0 \mathrm{~s}, 21.39 \mathrm{~ms}^{-1}\right)$ & $t_{a}, v_{a}$ & $\left(43 \mathrm{~s}, 2.99 \mathrm{~ms}^{-1}\right)$ \\
\cline { 2 - 5 } & $t_{b}, v_{b}$ & $\left(5 \mathrm{~s}, 18.29 \mathrm{~ms}^{-1}\right)$ & $t_{b}, v_{b}$ & $\left(50 \mathrm{~s}, 1.55 \mathrm{~ms}^{-1}\right)$ \\
\hline \multirow{2}{*}{$2^{\text {nd }}$ Attempt } & $t_{a}, v_{a}$ & $\left(0 \mathrm{~s}, 21.17 \mathrm{~ms}^{-1}\right)$ & $t_{a}, v_{a}$ & $\left(41 \mathrm{~s}, 3.33 \mathrm{~ms}^{-1}\right)$ \\
\cline { 2 - 5 } & $t_{b}, v_{b}$ & $\left(7 \mathrm{~s}, 16.85 \mathrm{~ms}^{-1}\right)$ & $t_{b}, v_{b}$ & $\left(47 \mathrm{~s}, 2.00 \mathrm{~ms}^{-1}\right)$ \\
\hline \multirow{3}{*}{$3^{\text {rd }}$ Attempt } & $t_{a}, v_{a}$ & $\left(0 \mathrm{~s}, 20.39 \mathrm{~ms}^{-1}\right)$ & $t_{a}, v_{a}$ & $\left(38 \mathrm{~s}, 3.77 \mathrm{~ms}^{-1}\right)$ \\
\cline { 2 - 5 } & $t_{b}, v_{b}$ & $\left(5 \mathrm{~s}, 17.29 \mathrm{~ms}^{-1}\right)$ & $t_{b}, v_{b}$ & $\left(46 \mathrm{~s}, 1.11 \mathrm{~ms}^{-1}\right)$ \\
\hline \multirow{2}{*}{$4^{\text {th } \text { Attempt }}$} & $t_{a}, v_{a}$ & $\left(0 \mathrm{~s}, 20.73 \mathrm{~ms}^{-1}\right)$ & $t_{a}, v_{a}$ & $\left(32 \mathrm{~s}, 6.21 \mathrm{~ms}^{-1}\right)$ \\
\cline { 2 - 5 } & $t_{b}, v_{b}$ & $\left(5 \mathrm{~s}, 17.84 \mathrm{~ms}^{-1}\right)$ & $t_{b}, v_{b}$ & $\left(38 \mathrm{~s}, 4.32 \mathrm{~ms}^{-1}\right)$ \\
\hline
\end{tabular}

